\title{
Regulation of Sucrase-Isomaltase Gene Expression Along the Crypt-Villus Axis of Rat Small Intestine
}

\author{
Peter G. Traber ${ }^{1}$
}

\begin{abstract}
Gastroenterology Division, Department of Internal Medicine, University of Michigan Medical School and Veterans Administration Medical Center, Ann Arbor, MI 48109
\end{abstract}

Received November 1, 1990

The expression of sucrase-isomaltase mRNA was investigated along the crypt-villus axis of rat small intestine using differentially isolated cells and in situ hybridization. A partial rat sucraseisomaltase cDNA was cloned which coded for a protein that was predicted to be $88 \%$ homologous to those encoded by the rabbit and human cDNAs. Southern blot analysis of rat genomic DNA indicated that the cDNA hybridized to a single gene. Northern blots of RNA extracted from subpopulations of intestinal epithelial cells that were isolated from villus and crypt compartments showed that this cDNA hybridized to a $6.5 \mathrm{~kb}$ band predominantly in villus RNA. In situ hybridization using 35 [S]-labeled RNA probes demonstrated that autoradiographic grains were detected over eptithelial cells located on villi with the greatest number of grains located at the cryptvillus junction and in the lower to mid-villus region; from mid-villus to the villus tip there was a decline in sucrase-isomaltase mRNA. We conclude that expression of sucrase-isomaltase as enterocytes emerge from intestinal crypts is regulated primarily at the level of mRNA accumulation which, most likely, is a result of activation of sucrase-isomaltase gene transcription. 1990

Academic Press, Inc.

The epithelial cells lining the small intestine are renewed every 2-3 days in rodents and every 56 days in humans (1-3). This occurs by continuous cell division of a stem-cell population located in intestinal crypts, migration of daughter cells along the villus and, finally, extrusion of senescent cells into the intestinal lumen $(3,4)$. Four epithelial cell phenotypes arise from stem cells including absorptive enterocytes (4), mucus-secreting goblet cells (5), entero-endocrine cells (6), and paneth cells (7). The majority of cells are enterocytes which constitute approximately $90 \%$ of cells in the crypt compartment and greater than $95 \%$ of cells on the villus (4). As enterocytes migrate towards the villus tip they acquire differentiated functions that allow the performance of specialized tasks including the absorption of nutrients and the metabolism of ingested xenobiotics. The molecular mechanisms that mediate this process have not been elucidated.

Sucrase-isomaltase (SI) is a membrane-anchored hydrolase that is synthesized as a single polypeptide, transported to the apical membrane of enterocytes, and catalyzes the cleavage of sucrase and isomaltase in the intestinal lumen into monosaccharides (8-10). SI enzymatic activity

1 The author wishes to acknowledge the technical assistance of Wei Wang in performance of the genomic Southern blot analysis. This work was supported by NIH grant DK41393, a VA Research Associate Award and Merit Review.

Abbreviations used in text: Sucrase-isomaltase $=S I$; Polymerase chain reaction $=P C R$. 
is found predominantly in villus cell apical membranes and is low in crypt cells as demonstrated using isolated intestinal epithelial cells (11-13). Beaulieu, et al. (14) recently suggested that the expression of SI enzymatic activity may be regulated by differential posttranslational processing of the protein in the crypt and villus compartments (14). Other proteins expressed in enterocytes, including liver fatty acid binding protein (15), cytochrome P450IIB1 (16), and aminopeptidase N (17) have previously been shown to be regulated at the level of mRNA abundance as cells migrate from crypt to villus. Therefore, the regulation of SI activity as described by Beaulieu, et al. (14) would represent a new mechanism for the regulation of differentiated gene expression in adult enterocytes.

The objective of these studies was to investigate the mechanism of SI gene expression along the rat small intestinal crypt-villus axis by measuring SI mRNA in isolated subpopulations of intestinal epithelial cells and by in situ hybridization.

\section{Methods}

Intestinal Epithelial Cell Isolation. RNA extraction and Northern and Southem Blot Analysis

Male, Fisher 344 rats weighing 200-250 g were housed in wire-floored cages and allowed free access to standard rat chow and water. Intestinal epithelial cells were isolated using a modification of the method described by Weiser (18) as recently described (19). RNA was isolated from cell fractions using the method described by Chomczynski and Sacchi (20). Poly-adenylated RNA was extracted from total RNA using oligo-dT cellulose and a micro-batch method.

For northern blot analysis, poly-adenylated RNA was separated in $2.2 \mathrm{M}$ formaldehyde and $1 \%$ agarose gels as previously described $(16,21)$ and the RNA transferred to nylon membranes (Hybond N, Amersham Corp., Arlington Heights, IL) using a Posiblot system (Stratagene, La Jolla, CA) as described by the manufacturer. RNA was bound to the nylon membrane by crosslinking with ultraviolet light and the membranes were hybridized and washed as previously described $(16,21)$.

For genomic Southern blot analysis, rat liver DNA was isolated, digested with restriction endonucleases and separated in an agarose gel. The DNA was transfered to nylon membrane and hybridized in the same fashion as for northern blots.

\section{Polvmerase Chain Reaction Amplification, cloning and sequencing of cDNA}

The amplification of cDNA using PCR was performed as previously described in our laboratory (21). The reverse transcriptase primer was homologous to bases 1263 to 1288 of the rabbit SI cDNA (5'-TCTGTCCATGGTCATGCAAATCTTG-3"); the PCR primers had Eco RI restriction sites incorportated into the 5' sequence (PCR 5'oligo: 5'-GTGGAATTCCTGCATTC CAGAACAATCTCCAACACAGGC-3'; PCR 3' oligo: 5'-GTGGAATTCTCCAGTATGCTG GCATTGCTGGTCGTCCAA-3'). The PCR product and plasmid vector were digested with EcoRI, separated in a low melting point agarose gel (Sea Plaque, FMC biochemicals), and ligations were performed "in gel" using T4 ligase (BRL) as described (21). Double-stranded DNA templates were sequenced by the dideoxynucleotide termination method (22) using modified $\mathrm{T} 7$ DNA polymerase (Sequenase 2.0, United States Biochemical, Cleveland, $\mathrm{OH}$ ) and $\left[{ }^{35} \mathrm{~S}\right] \mathrm{dATP}$ as described by the manufacturer.

\section{In Situ Hybridization}

In situ hybridization was performed as previously described in our laboratory (16) with modifications included from the method of Tyner, et al. (23). Freshly excised proximal jejunum was embedded in O. C. T. (Miles laboratories) and frozen by emersion in liquid nitrogen. Sections were cut at 6-8 um in a cryostat and placed on polylysine-treated slides. The sections were fixed by sequential emersion in $4 \%$ paraformaldehyde ( 2 min.) and ice-cold $70 \%$ ethanol (10 min.), hydrated through decreasing concentrations of ethanol, treated with $0.2 \%$ acetic anhydride

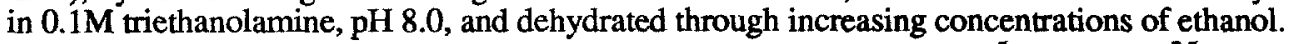

The sections were air dried and immediately hybridized with $1 \times 10^{5} \mathrm{cpm} / \mathrm{ul}$ of [35 $\mathrm{S}$-labeled RNA probe in a solution containing $50 \%$ formamide, $2 X$ SSC, $10 \mathrm{mM}$ dithiothreitol, $1 \mathrm{mg} / \mathrm{ml}$ nuclease free $E$. coli transfer RNA, $1 \mathrm{mg} / \mathrm{ml}$ salmon sperm DNA, and $2 \mathrm{mg} / \mathrm{ml}$ nuclease free 
bovine serum albumin. The single-stranded RNA probe was synthesized using the DNA template described in Results using the protocol recommended by Promega Biotech (Madison, WI) and [ ${ }^{35}$ S] UTP. Following synthesis, the DNA template was removed by treatment with RNase free DNase (RQ1 DNase, Promega), phenol:chloroform extracted, and ethanol precipitated. The slides were incubated at $65^{\circ} \mathrm{C}$ for 16 hours. Washes were performed as follows: 1) $50 \%$ formamide, 2 $\mathrm{X} \mathrm{SSC}$ at room temperature, $10 \mathrm{~min} ., 2) 2 \mathrm{X} \mathrm{SSC}$ at room temperature, $15 \mathrm{~min}$., 3) RNase A (10 $\mathrm{mg} / \mathrm{ml}$ ) in $0.5 \mathrm{M} \mathrm{NaCl}, 1 \mathrm{mM}$ EDTA at $37^{\circ} \mathrm{C}$ for $30 \mathrm{~min}$., 4) $0.5 \mathrm{M} \mathrm{NaCl}, 1 \mathrm{mM}$ EDTA at $37^{\circ} \mathrm{C}$ for $30 \mathrm{~min}$., 5) $2 X \mathrm{XSC}, 10 \mathrm{mM}$ beta-mercaptoethanol, $55^{\circ} \mathrm{C}$ for $\left.30 \mathrm{~min} ., 6\right) 0.1 \mathrm{X} \mathrm{SSC}, 10 \mathrm{mM}$ beta-mercaptoethanol, $5^{\circ} \mathrm{C}$ for $30 \mathrm{~min}$., twice.

After washing, slides were dehydrated through increasing concentrations of ethanol, dipped in liquid emulsion (Kodak NTB2, diluted 1:1 with water), and exposed in light-tight boxes at $4^{\circ} \mathrm{C}$. The slides were developed at intervals and stained with hematoxylin and eosin.

\section{Results}

\section{Cloning of partial rat sucrase-isomaltase cDNA and genomic Southern blot analysis}

A partial rat SI cDNA was amplified from RNA extracted from villus epithelial cells using PCR primers (Methods) that were designed using sequences of rabbit (8) and human SI cDNAs (24). The sequence of the partial rat cDNA, designated pRSI-1, and the predicted amino acid sequence is shown in Figure 1. The amino acid sequence was $88 \%$ homologous to the same region of both rabbit and human SI and the nucleic acid sequence showed 79 and $78 \%$ homology to rabbit and human, respectively.

The pRSI-1 cDNA was used for hybridization to Southern blot of rat genomic DNA that had been digested to completion with Eco RI, Pst I, Stu I, and Xba I (Figure 2). The cDNA hybridized to a single band in lanes digested with EcoRI, Pst I and Xba I and to only two bands in the lane digested with Stu I. Lanes 1 and 2 contained genomic DNA that had been spiked with the pRSI-1 plasmid and then digested with EcoRI to serve as positive controls for the hybridization. This pattern of hybridization suggested that the pRSI-1 cDNA recognized a single rat gene when hybridization and washing was performed at stringent conditions.

\section{Sucrase-isomaltase mRNA expression in isolated intestinal epithelial cell fractions}

Subpopulations of intestinal epithelial cells isolated differentially along the cyrpt-villus axis were used to investigate the ability of pRSI-1 to recognized SI mRNA and to grossly evaluate differences in expression between villus and crypt cell compartments. We have demonstrated that the method used for cell isolation was able to effectively separate subpopulations of epithelial cells into crypt and villus fractions as assessed by enzyme activities, DNA synthesis, mRNA expression, and light and electron microscopy (19). Northern blot analysis of polyadenylated RNA demonstrated that the pRSI-1 cDNA recognized a single mRNA species of approximately 6.5 $\mathrm{kb}$ (Figure 3). This corresponds to the size of the rabbit (8), human (24) and rat (25) SI mRNAs as previously reported by other authors. There were greater mRNA levels expressed in cells isolated from the villus compartment than from the crypt; the difference was 10-fold as determined by measurement of direct $\beta$-particle emmission from the membrane (Betascope, Betagen corp.).

The presence of crypt cell mRNA in the cell fractions was identified by hybridizing the same blot with cryptdin cDNA (pasb4/134 (26), a 315 bp mouse cryptdin cDNA was a gift of Dr. A. J. Ouellette, Harvard Medical School, Boston, MA). 


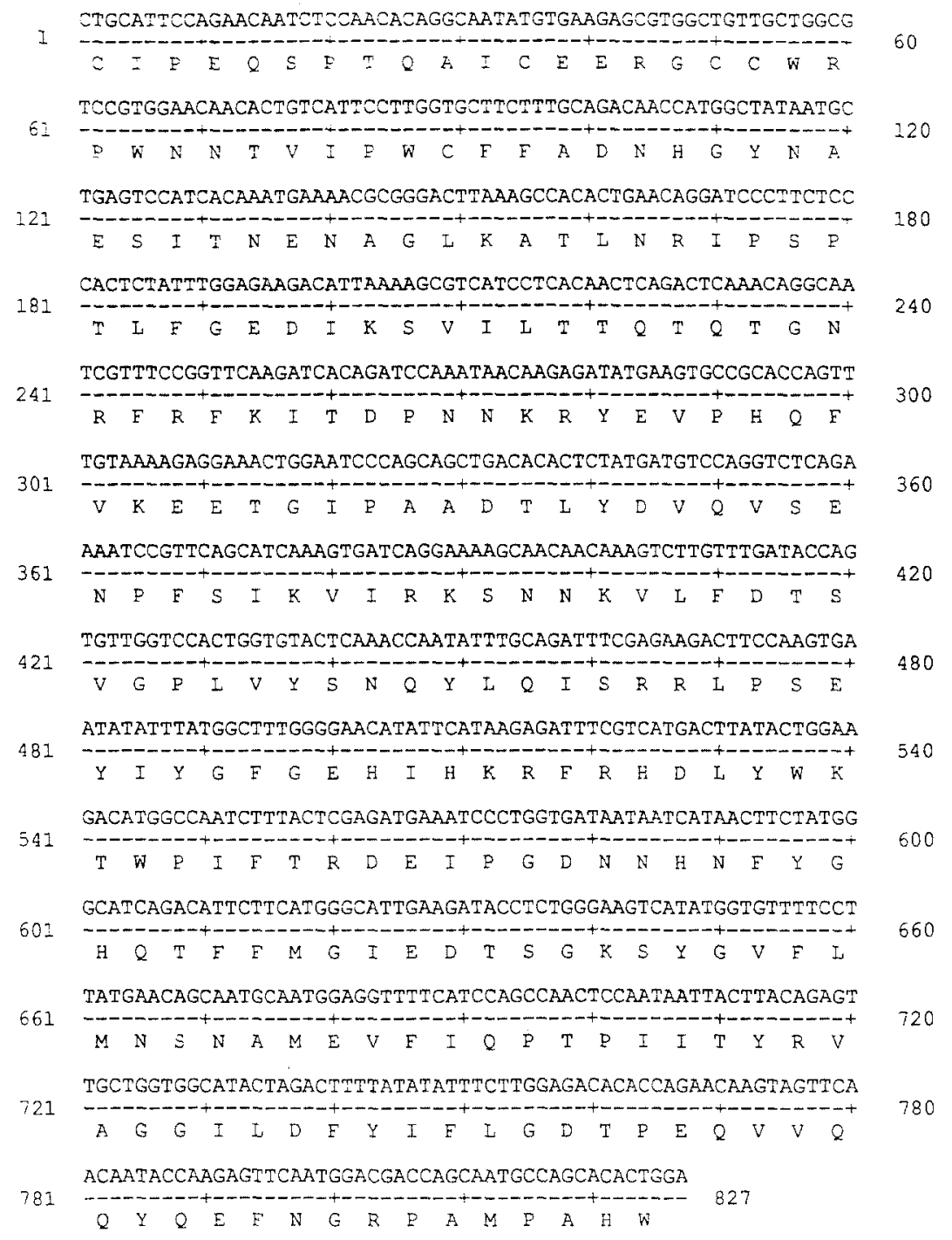

Figure 1. Sequence of pRSI-1.

Nucleotide sequence and derived amino acid sequence of the partial cDNA clone of rat sucraseisomaltase, pRSI-1 (the clone is from the isomaltase portion of the molecule).

\section{In situ hybridization}

In situ hybridization of rat jejunal sections with an antisense RNA probe synthesized from pRSI-1 demonstrated that autoradiographic grains were concentrated only over epithelial cells located on the villus (4a, bright field micrograph; $4 \mathrm{~b}$, darkfield micrograph). The greatest grain density was seen over epithelial cells located at the crypt-villus junction and in the lower to midvillus region with fewer grains over villus tip cells. This gradual decline in the number of grains from the villus base to the villus tip was observed in every villus of 3 separate hybridizations. The transition from cells that lacked sucrase mRNA to those that had maximal levels occured within several cell positions from the mouth of the crypt to the villus base (Figure $4 \mathrm{c}$ ). At the villus base many grains were over nuclei as well as in cytoplasm; in the mid-villus region the number of grains over nuclei decreased and the grains were concentrated in the cytoplasm just below the microvillus 


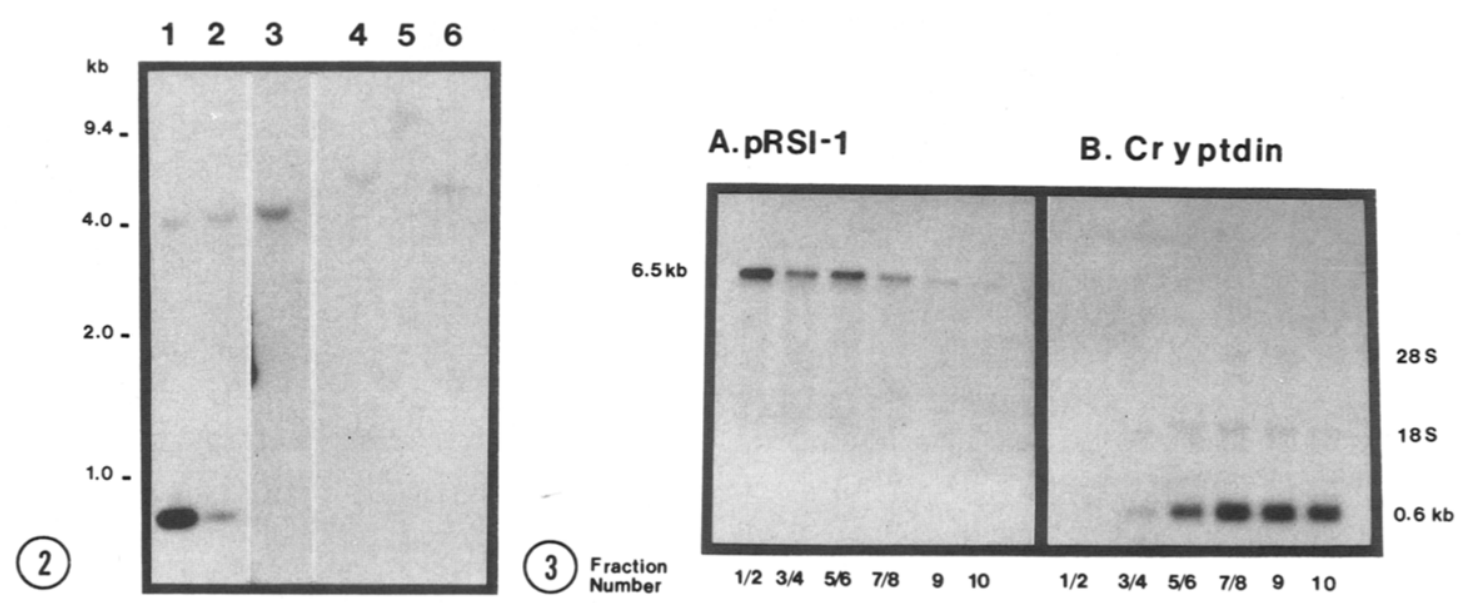

Figure 2. Southern Blot Analysis .

Genomic DNA was isolated from rat liver and 10 ug digested to completion with either Eco RI (lanes 1, 2 and 3), Pst I (lane 4), Stu I (lane 5), or Xba I (lane 6). The DNA samples in lanes 1 and 2 were spiked with 10 and 1 picogram of pRSI-1 DNA, respectively and served as hybridization controls. The digests were separated in a 1\% agarose gel, transfered to Nylon membrane and hybridized with gel-purified insert from pRSI-1 labeled with [32P]dATP (19). Washes were carried out as follows: 1 . 2 X SSC, $0.1 \%$ SDS at room temp., twice. 2. 1 X SSC, $1 \%$ SDS at $65^{\circ} \mathrm{C}$ for $30 \mathrm{~min}$. 3. $0.1 \times \mathrm{XSC}, 1 \% \mathrm{SDS}$ at $65^{\circ} \mathrm{C}$ for $30 \mathrm{~min}$. and 4. $0.1 \mathrm{XSSC}$, $0.1 \mathrm{XSDS}$ at $65^{\circ} \mathrm{C}$ for $30 \mathrm{~min}$. The blots were exposed to X-ray film for 10 days.

\section{Figure 3. Northern blot analysis.}

Polyadenylated RNA was extracted from epithelial cells isolated from along the crypt-villus axis as described in Methods. Cell fractions were combined as follows: $1 / 2,3 / 4,5 / 6,7 / 8,9$ and 10. $2 \mathrm{ug}$ of $\left(\mathrm{A}^{+}\right)$RNA was separated in a $1 \%$ agarose, $2.2 \mathrm{M}$ formaldehyde gel, transfered to a nylon membrane and sequentially hybridized with purified insert from pRSI-1 (panel $A$ ) and the cryptdin cDNA (panel B) (19). The autoradiograph in panel A was exposed for 3 hours; longer exposures did not reveal additional bands. The autoradiograph in panel B was exposed for 18 hours.

boarder. As a control, a homologous, sense probe synthesized from the opposite strand of pRSI-1 did not hybridize to epithelial cells (Figure 4d). Furthermore, when the antisense probe was used in the presense of 200-fold excess of unlabeled antisense RNA, hybridization to epithelial cells was blocked (4e).

\section{Figure 4. In situ hybridization of sections of adult rat jejunum.}

Representative results of one of 3 in situ hybridization experiments are presented. Each experiment contained 20 sections and the findings were consistent. Each of the sections presented in this series were allowed to expose for 3 days before developing. The sections were stained with hematoxylin and eosin following development.

4a: Sections of rat jejunum were hybridized with an antisense, single-stranded, $\left[{ }^{35}\right.$ S $]$-labeled RNA probe that was synthesized from the full-length insert of pRSI-1 (827 bp).

4b: View of section pictured in figure $4 \mathrm{a}$ as seen by dark field microscopy to accentuate silver grains.

4c: Higher power view of the crypt-villus junction of the section pictured in figure 4a.

4d: Sections of rat jejunum were hybridized with an antisense, single-stranded, [35S]-labeled RNA probe that was synthesized from the full-length insert of pRSI-1 ( $827 \mathrm{bp})$ and an excess ( 200 fold) of unlabeled antisense RNA.

4e: Sections of rat jejunum were hybridized with a sense, single-stranded, $\left[{ }^{35}\right.$ S]-labeled RNA probe that was synthesized from the full-length insert of pRSI-1 $(827 \mathrm{bp})$. 

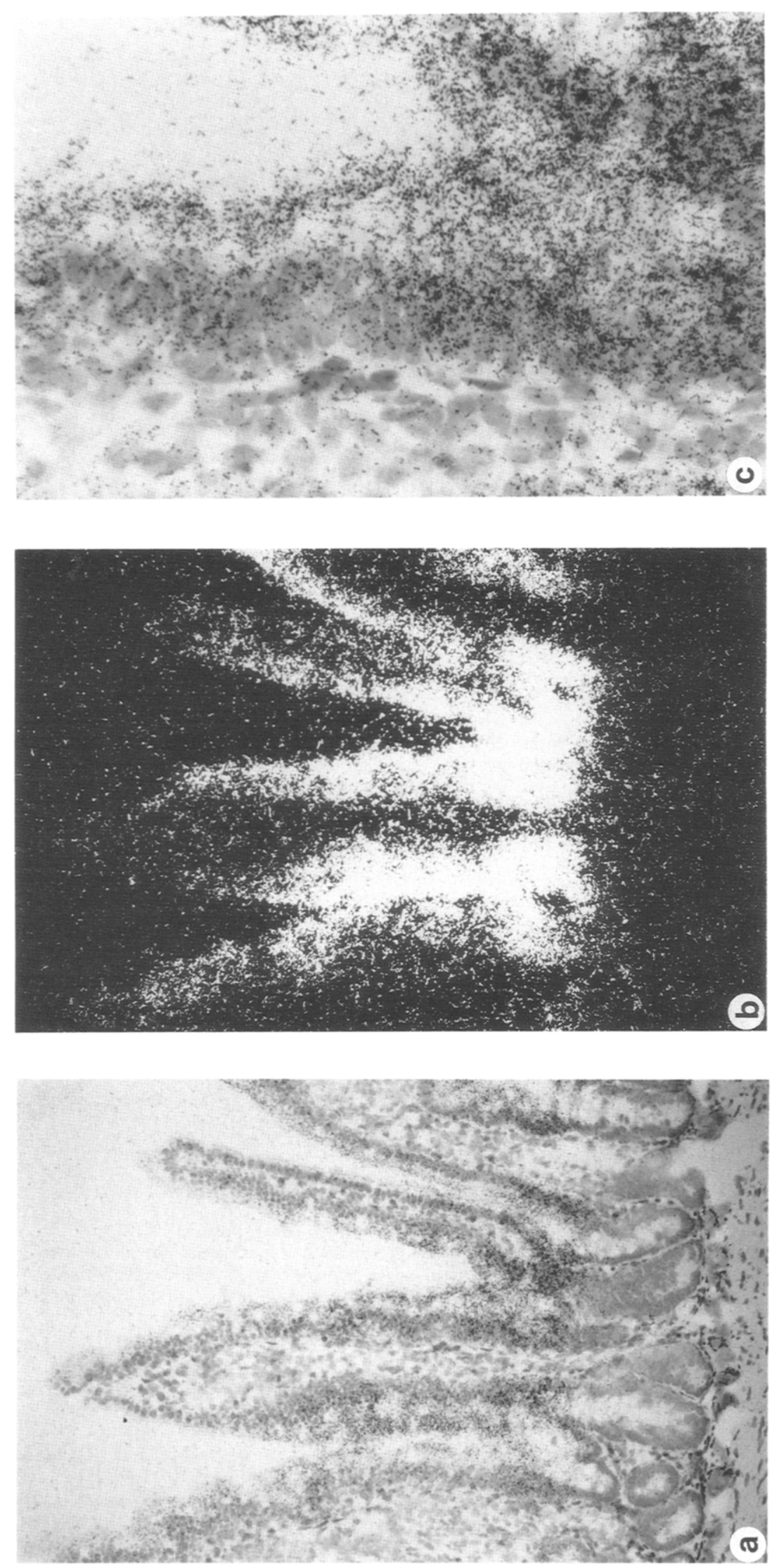

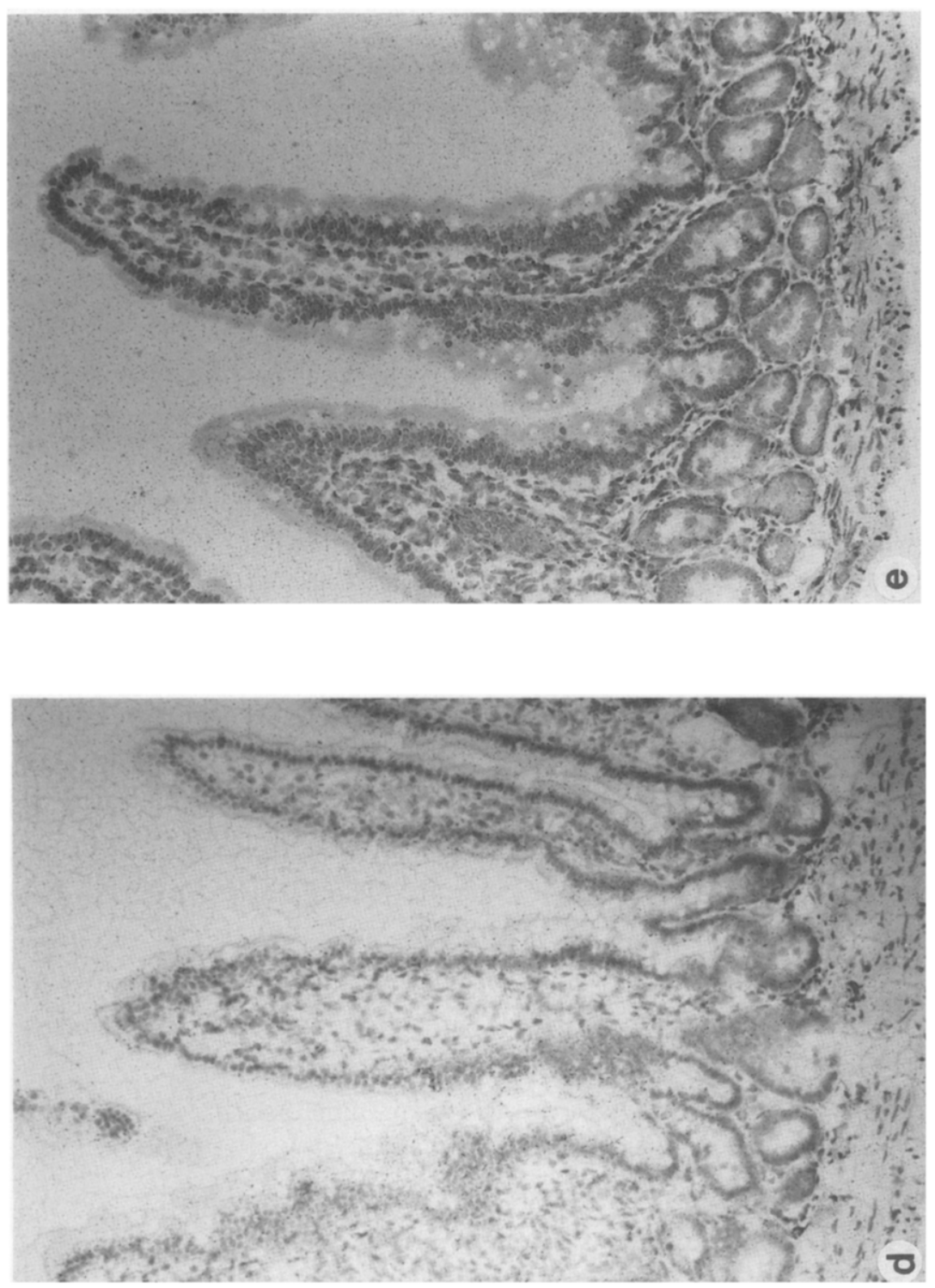


\section{Discussion}

In this study the distribution of SI mRNA was examined along the crypt-villus axis of adult rat small intestine using subpopulations of isolated epithelial cells and in situ hybridization. These experiments demonstrated that steady-state level of SI mRNA in intestinal epithelial cells constitutes a major mechanism for the control of SI gene expression as enterocytes differentiate while migrating from crypt to villus compartments.

The cDNA probe used for these studies was a partial SI cDNA (pRSI-1) derived from the isomaltase portion of the protein coding sequence. Several observations indicate that this cDNA is derived from rat SI mRNA: 1). The cDNA contains one open reading frame that codes for a protein sequence that is $88 \%$ homologous to both rabbit and human isomaltase, 2 ). The cDNA hybridizes to an mRNA species that corresponds to the reported size for SI mRNA in human, rat, and rabbit and, 3). An antisense RNA probe hybridized to the expected cell population in rat intestine. Genomic Southern blot analysis using stringent hybridization conditions suggested that the pRSI-1 cDNA hybridized to a single gene in rat. Therefore, these data suggest that our pRSI-1 recognizes a transcript derived from a single gene and, thus, validates its use for Northern analysis and in situ hybridization.

In situ hybridization demonstrating the absence of SI mRNA in jejunal crypt cells suggests that the gene is not transcribed in undifferentiated, proliferating cells located in crypts. It is possible that gene transcription is active with rapid degradation of the mRNA resulting in very low steadystate levels. This possiblity seems unlikely since autoradiographic grains were not seen over nuclei in crypt cells. In any event, undetectable levels of mRNA in crypt cells as assessed by in situ hybridization makes it unlikely that SI protein is present at significant levels in crypt cells. This conclusion is at odds with the recent observation that human jejunal crypt cells stained with a SIspecific monoclonal antibody as reported by Beaulieu, et al. (14). These authors presented data suggesting that differences in glycosylation of SI were responsible for differences in crypt and villus SI enzymatic activity. The same monoclonal antibodies have recently been used to stain normal human colon as well as colonic neoplasms; the findings suggested that SI is expressed in normal colonic crypts and in many adenomas (27). Leeper and Henning (25) recently reported that rat colon did not express SI mRNA using a rabbit SI cDNA. Species differences in the tissue distribution of SI expression may explain these discrepant observations between rat and human although this issue requires further investigation.

The level of expression of proteins associated with the differentiated enterocyte phenotype has been evaluated in rat by in situ hybridization for aminopeptidase $\mathrm{N}$ (17), cytochrome P450IIB1 (16), liver fatty acid binding protein (15), and, in this report, SI. In each case, little or no mRNA was detected in crypt cells and there was prompt appearance of mRNA in the upper crypt region as cells moved onto the base of the villus. Therefore, transcriptional activation of enterocyte genes at the crypt-villus junction may be a primary mechanism for expression of the differentiated phenotype as cells migrate along the crypt-villus axis.

Several studies have shown that maximal sucrase enzymatic activity is associated with enterocytes located in the mid-villus region $(12,13,18)$. Decreases in sucrase enzymatic activity in villus tip cells has been attributed to enzymatic degradation of the sucrase portion of the dimeric enzyme by luminal proteases (28). As shown in this study, an additional factor for declining levels 
of enzymatic activity in villus tip cells may be the decreased steady-state levels of SI mRNA which may be related to either a decrease in transcription of the gene, more rapid degradation of cytoplasmic mRNA, or a combination of both.

In conclusion, alterations in steady-state levels of SI mRNA along the crypt-villus axis of rat small intestine is a major mechanism for the regulation of SI gene expression. The evidence suggests that transcriptional activation of the gene is initiated as cells exit from the crypt, is maximal in the lower villus cells, and declines as cells migrate towards that villus tip. Evaluation of transcriptional activation and/or repression of the SI gene along the crypt-villus axis may provide a model for investigation of intestine-specific gene expression.

\section{References}

1. Lipkin, M. (1987) In Physiology of the Gastrointestinal Tract. (Johnson, L.R.,ed.) pp.255-284. Raven Press, New York.

2. Caimie, A.B., Lamerton, L.F. \& Steel, G.G. (1965) Exper. Cell. Res. 39, 528-538.

3. Gordon, J.I. (1989) J. Cell Biol. 108, 1187-1194.

4. Cheng, H. and Leblond, C.P. (1974) Am. J. Anat. 141, 461-480.

5. Cheng, H. (1974) Am. J. Anat. 141, 481-502.

6. Cheng, H. and Leblond, C.P. (1974) Am. J. Anat. 141, 503-520.

7. Cheng, H. (1974) Am. J. Anat. 141, 521-536.

8. Hunziker, W., Spiess, M., Semenza, G. and Lodish, H.F. (1986) Cell 46, 227-234.

9. Brunner, J., Wacker, H. and Semenza, G. (1983) Methods in Enzymology 96, 386-406.

10. Semenza, G.and Auricchio, S. (1989) In The metabolic basis of inherited disease (Scriver, C.R., Beaudet,A.L., Sey,W.S. and Valle, D., eds.) pp.2975-2997. McGraw-Hill, New York.

11. Koyama, S-Y. and Podolsky, D.K. (1989) J. Clin. Invest. 83, 1768-1773.

12. Dahlqvist, A. and Nordstrom, C. (1966) Biochim. Biophys. Acta 113, 624-626.

13. Hartmann, F., Owen, R. and Bissell, D.M. (1982) Am. J. Physiol. 242, G147-G155.

14. Beaulieu, J.F., Nichols, B. and Quaroni, A. (1989) J. Biol. Chem. 264, 20000-20011.

15. Iseki, S. and Kondo, H. (1990) J. Histochem. Cytochem. 38, 111-115.

16. Traber, P.G., Chianale, J., Florence, R., Kim, K., Wojcik, E. and Gumucio, J.J. (1988) J. Biol..Chem.. 263, 9449-9455.

17. Noren, O., Dabelsteen, E., Hoyer, P.E., Olsen, J., Sjostrom, H. and Hansen, G.H. (1989) FEBS Letter 259, 107-112.

18. Weiser, M.M. (1973) J. Biol. Chem. 248, 2536-2541.

19. Traber, P.G., Gumucio, D.L. and Wang, W. Isolation of intestinal epithelial cells for the study of differential gene expression along the crypt-villus axis (1990) Submitted.

20. Chomczynski, P. and Sacchi, N. (1987) Anal. Biochem. 162, 156-159.

21. Traber, P.G., Wang,W., McDonnell, M. and Gumucio, J. (1990) Mol. Pharmacol. 37,810819.

22. Sanger,F., Nicklen,S. and Coulson, A.R. (1977) Proc. Natl. Acad. Sci. U.S.A. 74, 54635467.

23. Tyner,A.L., Godbout,R., Compton,R.S. and Tilghman,S.M.(1990) J. Cell Biol. 110, 915927.

24. Green, F., Edwards, Y., Hauri, H.P., Povey, S., Ho, M.W., Pinto, M. and Swallow, D. (1987) Gene 57, 101-110.

25. Leeper, L.L. and Henning, S.J. (1990) Am. J. Physiol. 258, G52-G58.

26. Ouellette, A.J., Greco, R.M., James, M., Frederick, D., Naftilan, J. and Fallon, J.T. (1989) J. Cell Biol. 108, 1687-1695.

27. Beaulieu, J-F., Weiser, M.M., Herrera, L. and Quaroni, A. (1990) Gastroenterology 98, 1467-1477.

28. Goda, T., Quaroni, A. and Koldovsky, O. (1988) Biochem. J. 250, 41-46. 